Published in final edited form as:

Nat Catal. 2021 March ; 4(3): 251-258. doi:10.1038/s41929-021-00586-1.

\title{
Reversible $\mathrm{H}_{2}$ Oxidation and Evolution by Hydrogenase Embedded in a Redox Polymer Film
}

\author{
Steffen Hardt ${ }^{1}$, Stefanie Stapf ${ }^{1}$, Dawit T. Filmon ${ }^{1,2}$, James A. Birrell ${ }^{3}$, Olaf Rüdiger ${ }^{3}$, Vincent \\ Fourmond ${ }^{4}$, Christophe Léger ${ }^{4,},{ }^{*}$ Nicolas Plumeré ${ }^{1,2,{ }^{*}}$ \\ ${ }^{1}$ Center for Electrochemical Sciences (CES), Faculty of Chemistry and Biochemistry, Ruhr \\ University Bochum, Universitätsstr. 150, D-44780 Bochum, Germany \\ ${ }^{2}$ Campus Straubing for Biotechnology and Sustainability, Technical University Munich, \\ Schulgasse 22, 94315 Straubing, Germany \\ ${ }^{3}$ Max Planck Institute for Chemical Energy Conversion, Stiftstrasse 34-36, 45470 Mülheim an der \\ Ruhr, Germany \\ ${ }^{4}$ CNRS, Aix-Marseille Université, Laboratoire de Bioénergétique et Ingénierie des Proteínes, \\ Marseille, France
}

\section{Abstract}

Efficient electrocatalytic energy conversion requires the devices to function reversibly, i.e. deliver a significant current at minimal overpotential. Redox-active films can effectively embed and stabilise molecular electrocatalysts, but mediated electron transfer through the film typically makes the catalytic response irreversible. Here, we describe a redox-active film for bidirectional (oxidation or reduction) and reversible hydrogen conversion, consisting of [FeFe] hydrogenase embedded in a low-potential, 2,2'-viologen modified hydrogel. When this catalytic film served as the anode material in a $\mathrm{H}_{2} / \mathrm{O}_{2}$ biofuel cell, an open circuit voltage of $1.16 \mathrm{~V}$ was obtained - a benchmark value near the thermodynamic limit. The same film also acted as a highly energy efficient cathode material for $\mathrm{H}_{2}$ evolution. We explained the catalytic properties using a kinetic model, which shows that reversibility can be achieved despite intermolecular electron transfer being slower than catalysis. This understanding of reversibility simplifies the design principles of highly efficient and stable bioelectrocatalytic films, advancing their implementation in energy conversion.

Users may view, print, copy, and download text and data-mine the content in such documents, for the purposes of academic research, subject always to the full Conditions of use: http://www.nature.com/authors/editorial_policies/license.html\#terms

*leger@imm.cnrs.fr. nicolas.plumere@tum.de.

Author contributions

N.P., C.L., V.F., J.A.B. and O.R. conceived the research. S.H and S.S. developed and carried out the synthesis of the polymers, and performed all electrochemical experiments involving the polymer. D.T.F. developed and carried out the synthesis of the dendrimer, and performed all electrochemical experiments involving the dendrimer. S.H. contributed with the fuel cell and electrolyser experiments. O.R. contributed with direct electron transfer experiments. V.F. performed electrochemical modeling and data analysis. J.A.B. contributed the hydrogenase. All authors contributed to writing the manuscript.

Competing interests

The authors declare no competing interests. 


\section{Introduction}

The distinction between bidirectional and reversible molecular catalysts of redox reactions has recently been emphasised. ${ }^{1-3}$ Bidirectional catalysts can catalyse a reaction at a significant rate in either direction. Reversible catalysts are a subgroup of bidirectional catalysts that catalyse the reaction at a significant rate in response to even a small departure from equilibrium, i.e., in the case of a redox reaction, at a small overpotential. ${ }^{1-3}$ Reversible catalysts are required in energy conversion to minimise energy dissipation and thus to increase the energy efficiency of the process. Several reversible synthetic molecular catalysts $^{2,4-8}$ and many redox enzymes ${ }^{1,9-14}$ catalyse reactions of practical interest, such as the transformations of $\mathrm{H}_{2}$ and $\mathrm{CO}_{2}$, at very high rates and reversibly. Their global implementation in sustainable energy schemes also requires that these catalysts are scalable and robust. ${ }^{15}$ Some bioinspired and biological catalysts are made of earth-abundant elements and could thus fulfill the scalability requirement, ${ }^{16-18}$ but their robustness is often insufficient for direct implementation in energy converting devices, especially because of their sensitivity to oxidative stress and molecular oxygen. ${ }^{19-23}$ A recently proposed solution to that problem, based on the incorporation of fragile catalysts into redox-active films serving as a protection matrix against oxidative deactivation, ${ }^{24-31}$ enabled us to use the highly $\mathrm{O}_{2}$-sensitive $[\mathrm{FeFe}]$ hydrogenase ${ }^{32,33}$ even under operating fuel cell conditions. ${ }^{34,35}$ However, the integration of biocatalysts such as hydrogenases or $\mathrm{CO}_{2}$-reducing enzymes into redox films has systematically led to a loss of their intrinsic reversibility: ${ }^{34,26-31}$ catalysis occurs only at a significant overpotential, which results in a dissipation as heat of a fraction of the input energy. Similarly, a large driving force is also typically required to obtain fast mediated electron transfer when unidirectional enzymes are immobilised in redox-active films. ${ }^{36,37}$ To the best of our knowledge, reversible catalysis in a redox-active bioelectrocatalytic film has neither been observed, nor explored theoretically.

Here, we show that reversibility of the catalysis by the [FeFe] hydrogenase from Desulfovibrio desulfuricans ( $D d \mathrm{HydAB}$ ) is preserved, over a large $\mathrm{pH}$ range, upon integration of the enzyme into a 2,2'-viologen based redox-hydrogel whose potential matches that of the $2 \mathrm{H}^{+} / \mathrm{H}_{2}$ couple at $\mathrm{pH} 7$ (Fig. 1). We show that this reversibility is an advantage when the electrode is used either as an anode in a $\mathrm{H}_{2} / \mathrm{O}_{2}$ fuel cell or as a cathode in a water electrolyser: combining the reversible hydrogenase electrode with an $\mathrm{O}_{2}$ reducing biocathode gives a fuel cell whose open circuit voltage value is unambiguously attributed to the $\mathrm{H}_{2} / \mathrm{O}_{2}$ catalysed reactions, almost reaching the thermodynamic limit of $1.23 \mathrm{~V}$. The reversible hydrogenase electrode also evolves $\mathrm{H}_{2}$ with $100 \%$ Faraday efficiency. We propose a kinetic model that explains how both the kinetics and thermodynamics of intermolecular ET between the mediator and the catalyst determine the properties of the system, including the effective catalytic bias, which is simply tuned by changing the $\mathrm{pH}$.

\section{Results}

\section{Design of the Low Potential 2,2'-Viologen Modified Polymer}

Freely diffusing mediators such as $4,4^{\prime}$-viologen species have been used to mediate reversible hydrogenase catalysis, ${ }^{27,39-41}$ but when similar 4,4'-viologen moieties are covalently tethered to polymer or dendrimer backbones, electron transfer (ET) and catalysis 
with hydrogenases becomes unidirectional. ${ }^{25-27,31,34}$ We hypothesised that this is due to the functionalisation of the 4,4'-viologen moiety and its local environment within the polymeric matrices, making its redox potential more positive by as much as $150 \mathrm{mV}$ (Fig. 1). Here, we used a low potential viologen based on alkylated 2,2'-bipyridine to compensate for the potential shift induced by tethering to the matrix backbone (Fig. 1b). The redox potentials of 2,2'-viologens $\mathbf{V 2}$ (Fig. 1a) are typically more negative than that of 4,4'-viologens ${ }^{42}$ (Fig. 1a and $1 \mathrm{~b}$ ), because the strain imposed by the ring structure destabilises the radical cation and the methyl substituents on the viologen core are electron donating. ${ }^{43}$ A hydroxyl group on the propylene bridge serves as the anchoring group (Supplementary Method 1 and Supplementary Figure 1 for the synthetic procedure and Supplementary Figures 2 - 5 for full characterisation). Cyclic voltammograms of V2 show a pair of peaks (Supplementary Fig. 6) attributed to the first reduction of the viologen dication $\left(\mathrm{V} 2^{++}\right)$to the radical cation states $\left(\mathrm{V}^{\bullet+}\right)$. The redox potential of the $\mathrm{V} 2^{\bullet+} / \mathrm{V}^{++}$couple is $-585 \mathrm{mV} \pm 1 \mathrm{mV}(n=3)$ Vs SHE (172 $\mathrm{mV}$ more negative than the $2 \mathrm{H}^{+} / \mathrm{H}_{2}$ Nernst potential at $\mathrm{pH} 7$ ), and is mostly independent of $\mathrm{pH}$ and of the presence of $\mathrm{H}_{2}$.

The 2,2'-viologen moiety was covalently grafted to a polyvinyl-alcohol backbone via a diisocyanate linker (Supplementary Method 1 for the synthetic procedure and Supplementary Figures 7 - 17 for full characterisation), which yielded polymer PV2 with a high load of viologen (w/w 48\% $\pm 10 \%$, Supplementary Figure 18; Supplementary Figures 19- 21 for full characterization). A similar 2,2'-viologen moiety bearing an additional thioacetate crosslinking functionality was also synthesised and bound to a poly(amidoamine) dendrimeric scaffold using the same isocyanate coupling strategy to yield dendrimer DV2 (Supplementary Method 2 and Supplementary Figure 22 for the synthetic procedure and Supplementary Figures 23 - 32 for full characterisation) with a high viologen functionalisation yield (99\%, Supplementary Note 1). The polymer-based hydrogels are advantageous from an application point of view because of their scalability and suitability for generation of high catalytic currents. However, viologen modified polymers tend to aggregate, which makes the formation of very thin films inaccessible. In contrast, viologen modified dendrimers with crosslinking functionalities can be used to produce homogeneous thin films, ${ }^{44,45}$ whose thickness and current response are proportional to the amount of catalyst they embed. ${ }^{24}$

The viologen modified polymer PV2 was deposited onto the surface of a glassy carbon electrode by drop-casting. Cyclic voltammograms of the modified electrode revealed a redox potential for the $\mathrm{PV} 2^{\bullet+} / \mathrm{PV}^{++}$couple in the polymer film of $E_{\mathrm{M}}(\mathrm{PV} 2)=-429 \pm 8 \mathrm{mV} V s$ SHE $(n=4)$, which is $156 \mathrm{mV}$ more positive than the potential of the freely diffusing viologen analogue V2 (Supplementary Figure 33). Hence, the attachment to the polymer backbone brings the redox potential of the viologen within the film of PV2 close to the Nernst potential of the $2 \mathrm{H}^{+} / \mathrm{H}_{2}$ couple at $\mathrm{pH} 7$. Moreover, it is independent of $\mathrm{pH}$, the presence of $\mathrm{H}_{2}$ and the presence of hydrogenase within the film. The electrochemical behaviour of a film made of dendrimer DV2, modified with the same viologen units, is very similar (Supplementary Figures 34 - 37). 


\section{Reversible Catalysis with PV2 / Hydrogenase Electrodes}

Electrodes modified with [FeFe] hydrogenase from Desulfovibrio desulfuricans (DdHydAB) catalyse both $\mathrm{H}_{2}$ oxidation and production under conditions of direct electron transfer (DET) (Fig. 2a) or mediated electron transfer (MET) within the film of PV2 (Fig. 2b,c). The catalytic currents are high (in the $\mathrm{mA} \mathrm{cm}^{-2}$ range for both electrode types and in both directions of the $\mathrm{H}^{+} / \mathrm{H}_{2}$ reaction) considering that planar electrodes are used. The hydrogenase undergoing DET shows a change in catalytic bias (the ratio $i_{\text {ox }} / i_{\text {red }}$ ) in favour of $\mathrm{H}_{2}$ production and a decrease in catalytic potential (the midpoint potential of the wave $E$ cat) as the $\mathrm{pH}$ decreases (Fig. 2a), which is in agreement with previous reports on DET of hydrogenases from various organisms. ${ }^{46-49}$ With the hydrogenase embedded within the viologen modified polymer film undergoing MET, the bias $i_{\text {ox }} / i_{\text {red }}$ also changes in favour of $\mathrm{H}_{2}$ production as the $\mathrm{pH}$ decreases (Fig. 2b,c), but the catalytic waves remain centred on the $\mathrm{pH}$-independent redox potential of the viologen (Fig. 2b). The same behaviour is observed for the hydrogenase embedded in the viologen modified dendrimer film (Supplementary Figure 38). This demonstrates that the redox-active film tunes the apparent catalytic properties of the embedded catalyst.

Control experiments based on buffer exchange and multiple cycle experiments exclude contributions from unbound viologen (Supplementary Figures 39 and 40), and thus confirm that ET is mediated by the viologen moieties that are tethered to the backbone of the immobilsation matrix. Moreover, the $\mathrm{H}_{2}$ oxidation current is independent of $\mathrm{H}_{2}$ at high $\mathrm{H}_{2}$ concentration (Supplementary Figure 41), excluding limitation from $\mathrm{H}_{2}$ mass transport. This shows that catalysis with the hydrogenase/PV2 modified electrodes operates under thin film conditions. ${ }^{24,50-52}$ Moreover, the catalytic current for $\mathrm{H}_{2}$ oxidation or production increases in proportion to the amount of dendrimer/enzyme mixture deposited onto the electrode when the amount is small, and then tends to a plateau (Supplementary Figure 42). This demonstrates that the amount of the immobilised catalyst defines the catalytic current in the thinnest films (catalysis limited regime) and that charge transfer via electron hopping within the film defines the current for thicker films (electron transfer limited regime). Under catalysis limited conditions, the concentrations of $\mathrm{H}_{2}$ and reduced/oxidised forms of the mediators are homogenous in the film. ${ }^{50,51,53}$

\section{Kinetic Model of Mediated, Bidirectional Electrocatalysis}

The comparison of Fig. $2 \mathrm{a}$ and $2 \mathrm{~b}$ shows that interfacing the hydrogenase either directly (Fig. 2a) or via the viologen mediator embedded into the films (Fig. 2b) significantly changes the current response and, in particular, the catalytic bias (compare the triangles and squares in Fig. 3c). The DET responses can be modelled by a mechanism consisting of two electron transfer steps and one chemical reaction step (EEC-mechanism) taking into account slow interfacial ET. $46,54-56$ The MET response is much simpler, as it can be modelled by a 1-electron sigmoid (red line in Figure 3b), whose midpoint potential (the catalytic potential) is independent of $\mathrm{pH}$. To explain this behaviour, we propose a simple theoretical model of the bidirectional current response of a 1-electron redox enzyme embedded in a thin film of polymer with a redox moiety that acts as a mediator, assuming the rates of catalysis and the concentration of reduced and oxidised viologen are homogeneous in the film. We show in Supplementary Note 2 that the current response reads: 


$$
i=\frac{i_{o x} \exp F\left(E-E_{\mathrm{cat}}\right) / R T-i_{\text {red }}}{1+\exp F\left(E-E_{\mathrm{cat}}\right) / R T}
$$

in which $i_{O X}$ and $i_{\text {red }}$ are the limiting oxidative and reductive currents, respectively, as defined in Fig. $3 b$, and the midpoint potential of the wave, $E_{\text {cat }}$, is given by

$$
E_{\mathrm{cat}}=E_{\mathrm{M}}+\frac{R T}{F} \ln \frac{\alpha / \delta+1}{\alpha \delta+1}
$$

in which: $\alpha=A^{\sum} \sqrt{k_{a} k_{b}} /\left(k_{\mathrm{Ox}}+k_{\mathrm{red}}\right)$ and $\delta=\sqrt{k_{a} / k_{b}}=\exp \left[F\left(E_{\mathrm{M}}-E_{e}\right) / 2 R T\right]$. The rate constants are depicted in Fig. 1: $k_{\mathrm{a}}$ and $k_{\mathrm{b}}$ are the bimolecular rate constants for the oxidation and reduction of the enzyme by the mediator, $k_{\mathrm{ox}}$ and $k_{\text {red }}$ are the $1^{\text {st }}$ order rates of $\mathrm{H}_{2}$ production and evolution by the enzyme, $\mathrm{A}{ }_{\text {is }}$ the total concentration of viologen in the film, $E_{\mathrm{M}}$ is the potential of the mediator, and $E_{\mathrm{e}}$ is the potential of the enzyme.

Equation 2 shows that $E_{\text {cat }}$ changes from the potential of the mediator to the potential of the enzyme as the ratio of the rate of intermolecular ET over the rate of catalysis increases (Fig. 3a). Equation 1 perfectly reproduces the experimental catalytic currents of Fig. $2 \mathrm{~b}$ (as exemplified in Fig. 3b), and we determined a value for $E_{\text {cat }}$ of $-435 \pm 3 \mathrm{mV} v S \mathrm{SHE}$ at $\mathrm{pH} 7$, identical to the potential of the mediator $\left(E_{\mathrm{M}}(\mathrm{PV} 2)=-429 \pm 8 \mathrm{mV}\right.$ vs SHE$)$. We found that $E_{\text {cat }}$ equals $E_{\mathrm{M}}(\mathrm{PV} 2)$ at all $\mathrm{pH}$ values below 8 and deviates only slightly under more alkaline conditions (Fig. 3c). Similarly, the catalytic potential is also equal to the potential of the mediator in the case of the hydrogenase embedded in the DV2 films (Supplementary Figure 43a). Using Equation 2 we conclude that intermolecular ET is slower than catalysis $(a \ll 1$, which corresponds to the shaded area in Fig. 3a).

Using the constraint that the current is zero at the equilibrium potential (i.e. when $E=E_{\mathrm{eq}}$ ), equation 1 imposes a strict relationship between the catalytic bias (the ratio $i_{\text {ox }} / i_{\text {red }}$ ), the catalytic potential $\left(E_{\text {cat }}\right)$ and the Nernst potential of the $2 \mathrm{H}^{+} / \mathrm{H}_{2}$ couple $\left(E_{\text {eq }}\right)$ :

$$
\frac{i_{\mathrm{ox}}}{i_{\text {red }}}=\exp \frac{F\left(E_{\mathrm{cat}}-E_{\mathrm{eq}}\right)}{R T}
$$

From the above observation that $E_{\text {cat }}=E_{\mathrm{M}}$, we conclude that the catalytic bias should be independent of the potential of the enzyme:

$$
\frac{i_{\mathrm{ox}}}{i_{\text {red }}}=\exp \frac{F\left(E_{\mathrm{M}}-E_{\mathrm{eq}}\right)}{R T}
$$

Equation 4 predicts that the catalytic bias changes with $\mathrm{pH}$ in our experimental case, since $E$ $\mathrm{M}(\mathrm{PV} 2)$ is $\mathrm{pH}$-independent and $E_{\text {eq }}$ shifts $-60 \mathrm{mV}$ per $\mathrm{pH}$ unit. The prediction is shown as a red line in Fig. 3d, together with the experimental values as squares. The very good agreement between the two shows that intermolecular ET is slower than catalysis over the whole $\mathrm{pH}$ range, yet this does not impair reversibility between $\mathrm{pH} 6.6$ and 8.6 (Fig. 2b). 


\section{Use of Reversible Electrodes in Fuel Cells and Electrolysers}

The use of an electrode that reversibly catalyses $\mathrm{H}_{2}$ oxidation and $\mathrm{H}_{2}$ production should maximise the energy conversion efficiency in $\mathrm{H}_{2} / \mathrm{O}_{2}$ fuel cells (high voltage) and in electrolysers for $\mathrm{H}_{2}$ production. The hydrogenase/PV2 bioanode showed significant stability for more than 15 hours in the $\mathrm{H}_{2}$ oxidising and $\mathrm{H}_{2}$ producing modes (Supplementary Figure 45), which made it possible to test its fuel cell and electrolyser performance (Fig. 4). The fuel cells were built from a hydrogenase/PV2 film either on a flat glassy carbon electrode (Fig. 4a) or on a large surface area gas breathing electrode (Fig. 4b). The $\mathrm{H}_{2}$ oxidising bioanodes were combined with carbon felt electrodes modified with the enzyme bilirubin oxidase from Myrothecium verrucaria (electrode characterisation is detailed in Supplementary Figure 46). ${ }^{57}$ This biocathode allows $\mathrm{O}_{2}$ reduction to occur at small overpotential. ${ }^{57-59}$ The previously reported mechanism by which the redox polymer protects the enzyme from $\mathrm{O}_{2}$, relies on the reduction of $\mathrm{O}_{2}$ in the outer layers of the thin redox-active films before it reaches the hydrogenase in the inner layers. ${ }^{24}$ This mechanism remained operational in the films characterised here, as demonstrated by the PV2-catalysed $\mathrm{O}_{2}$ reduction (Supplementary Figure 47) and the stable catalytic current for $\mathrm{H}_{2}$ oxidation under a mixed gas-feed of $\mathrm{H}_{2}$ and $\mathrm{O}_{2}$ (Supplementary Figure 48). Moreover, although the anode based on the flat glassy carbon electrode experiences very oxidative potentials (of up to 0.79 $\mathrm{V} v s$ SHE) due to the anode limiting conditions imposed by the use of an oversized cathode (Supplementary Figure 49), the embedded hydrogenase remains functional, demonstrating efficient protection of the enzyme from chloride-dependent high potential deactivation ${ }^{60}$ by PV2 (Supplementary Figure 50). This dual protection from aerobic and anaerobic oxidative stress made it possible to implement the reversible hydrogenase-PV2 anode in either a one or a two-compartment $\mathrm{H}_{2} / \mathrm{O}_{2}$ fuel cell setup.

The power curves were almost identical for the one-compartment and for the twocompartments setup based on the flat glassy carbon electrode (Fig. 4a and Supplementary Figure 51) and exhibited a maximum power output of $147 \pm 14 \mu \mathrm{W} \mathrm{cm}{ }^{-2}$, a maximum current output of $163 \pm 26 \mu \mathrm{A} \mathrm{cm}^{-2}$ and an open circuit voltage (OCV) of $1.163 \pm 0.005 \mathrm{~V}$ ( $n$ $=3$ ). Power density and current density were increased by one order of magnitude to values of $1.06 \pm 0.26 \mathrm{~mW} \mathrm{~cm}^{-2}$ and $3.0 \pm 0.9 \mathrm{~mA} \mathrm{~cm}^{-2}$, while a high OCV value $(1.149 \pm 0.012 \mathrm{~V}$, $n=3$ ) was conserved (Fig. $4 \mathrm{~b}$ ) by using high surface area carbon electrodes modified with PV2/DdHydAB operated in a gas breathing mode in a two-compartment setup (Supplementary Figure 52). The use of the large surface area electrodes for both anode and cathode leads to high catalytic currents for both half-cells (Supplementary Figure 53a), which explains the difference in shape of the power curve (Fig. 4b) in comparison to the one of the fuel cell based on the flat glassy carbon electrodes (Fig. 4a) operated under anode limiting conditions (Supplementary Figure 49).

The high OCV values obtained for the fuel cells based on PV2/DdHydAB anodes match those previously reported for biofuel cells using hydrogenase under conditions of DET, ${ }^{63-67}$ with the added advantage of efficient protection from $\mathrm{O}_{2}$ (Supplementary Figure 48) and high potential (Fig. 2b and Supplementary Figure 50) for the hydrogenase anode incorporated in PV2. Earlier examples of $\mathrm{H}_{2} / \mathrm{O}_{2}$ biofuel cells based on bioanodes with the PV1 type of polymer designed for hydrogenase protection had an OCV lower or equal to 
$1.08 \mathrm{~V} .{ }^{26,34} \mathrm{~A}$ value of $1.13 \mathrm{~V}$ has also been reported, ${ }^{68}$ but it included a pseudo-capacitance contribution which increases the OCV value but does not contribute significantly to power generation. ${ }^{69}$

In addition to its use as a bioanode in the $\mathrm{H}_{2} / \mathrm{O}_{2}$ biofuel cell, we could use the reversible PV2/DdHydAB electrode as a biocathode in an electrolyser for $\mathrm{H}_{2}$ production (Fig. $4 \mathrm{c}$ and Supplementary Figure 54). The catalytic currents were high $\left(6.2 \pm 2.1 \mathrm{~mA} \mathrm{~cm}^{-2}\right.$ at $-0.62 \mathrm{~V}$ vs SHE, $n=4$ ) and stable, so that the hydrogen produced at the cathode could be detected and quantified by gas chromatography even at overpotentials as low as $12 \mathrm{mV}$ (Supplementary Figure 54d). High selectivity with Faraday efficiencies close to $100 \%$ and low overpotential requirements led to energy conversion efficiencies of the $\mathrm{H}_{2}$ producing half cell (calculated based on a reversible $\mathrm{O}_{2}$ producing half-cell ${ }^{61,62}$ ) in excess of $95 \%$ even for current densities as high as $4 \mathrm{~mA} \mathrm{~cm}^{-2}$ (Fig. 4c).

\section{Discussion}

In this paper, we have demonstrated the possibility of reversible catalysis under conditions of mediated ET in a thin film. Reversibility is evidenced by the catalytic response cutting sharply across the potential axis at the equilibrium potential, allowing the fuel cell voltage to be at least $82 \mathrm{mV}$ higher than in previous reports. The observed open circuit voltage value $(1.16 \mathrm{~V})$ was unambiguously attributed to the $\mathrm{H}_{2} / \mathrm{O}_{2}$ catalysed reactions, and close to the thermodynamic limit $(1.23 \mathrm{~V})$, with the residual overpotential resulting from the cathodic reactions. ${ }^{70}$ Decreasing the overpotential for catalysis conserves energy that would otherwise be released as heat: a potential source of damage if the catalytic film is confined in a fuel cell stack. The same conclusions hold for the reverse reaction for use in electrolysers: the reversible hydrogenase electrode generates high current densities for $\mathrm{H}_{2}$ production at minimal overpotential, thus ensuring maximised efficiency for the conversion of electricity into chemical energy.

In order to identify the requirements for reversibility, we have described a model of bidirectional mediated electrocatalysis, focusing on the case of a thin film. Our assumptions are different from those of the only existing previous model of mediated bidirectional catalysis. ${ }^{41,71}$ First, Kano, Ikeda and coworkers considered planar semi-infinite diffusion (which is not relevant to the case discussed here, a film of finite thickness). Second, they implicitly assume that the catalytic transformation is infinitely fast compared to intermolecular ET, whereas we explicitly consider the competition between the two halfreactions: reaction of the enzyme to produce and consume $\mathrm{H}_{2}$, and intermolecular ET between the enzyme and the viologen. We reached the conclusion that reversible catalysis can operate under two distinct regimes (Fig. 3a): The fast catalysis regime in which the redox potential of the electron mediator defines both the position of the catalytic wave ( $E_{\text {cat }}$ $=E_{\mathrm{M}}$ ) and the catalytic bias as a function of $\mathrm{pH}$ (eq. 4 ) and, the fast electron transfer regime in which the redox potential of the enzyme's active site defines the position of the wave ( $E$ cat $=E_{\mathrm{e}}$ ). These conclusions on the theory of reversibility in MET are the same as in the case of DET with an unidirectional enzyme that embeds a one electron redox relay between the surface and the active site. ${ }^{72}$ 
The fact that the potential of the mediator is $\mathrm{pH}$-independent while the potential of the enzyme is $\mathrm{pH}$-dependent gives a decisive criterion for experimentally determining the relative kinetics of ET. The position of the catalytic wave in the MET case is mostly independent of $\mathrm{pH}$ and centered on the mediator potential demonstrating operation in the fast catalysis regime (Fig. 3c). This is further corroborated by the catalytic bias that changes as a function of $\mathrm{pH}$ and the properties of the mediator, but is independent of the properties of the enzyme (Fig. 3d). An important conclusion here is that fast intermolecular ET between the mediator and the enzyme is not a requirement for observing a reversible response.

Under these conditions of fast catalysis, the requirement to experimentally achieve catalytic reversibility and high catalytic currents is a close match between the redox potentials of the mediator and the enzyme, because the catalytic bias depends exponentially on the difference between the two (Equation 4 and Fig. 3d). This is highlighted by the $D d H y d A B$ hydrogenase integrated in the redox-active polymer PV2 film with matching potential at neutral $\mathrm{pH}$ conditions, which shows a transition from unidirectionality at $\mathrm{pH} 6.4$ to reversibility around neutral $\mathrm{pH}$ and again to unidirectionality at $\mathrm{pH} 8.8$ (Fig. 2c). Reversibility in a broader $\mathrm{pH}$ range can occur in the fast ET regime as observed for the hydrogenase in the DET configuration (Fig 2a). ${ }^{46}$ The film properties that define reorganisation energy and interactions between the redox partners (Marcus model) could serve as a primary optimisation target to enhance ET, and thus transition the MET systems into the fast ET regime.

In conclusion, reversibility in mediated redox-active films can theoretically take place either in the fast electron transfer regime or in the fast catalysis regime, and we show that the latter is accessible experimentally. From a practical perspective, reversibility in electrocatalytic films is important for energy conversion applications because it combines the advantage of high current densities at low overpotential with the possibility for robust catalysis owing to the intrinsic protecting feature of the redox matrix. ${ }^{24}$ Overall, this understanding of the different regimes for reversibility and the demonstration of its practical usefulness for conversion of small molecules may guide the future design of electrocatalytic films that have, until now, shown only unidirectionality despite the reversible nature of the catalysts.

\section{Methods}

\section{Materials and instrumentation}

The electrochemical measurements were carried out with a three-electrode setup consisting of a GCE-working electrode (for MET) or a PGE-working electrode (for DET), a Pt-counter electrode and an $\mathrm{Ag} / \mathrm{AgCl} 3 \mathrm{M} \mathrm{KCl}$ (for MET) or a saturated calomel (for DET) reference electrode. All MET CVs of DdHydAB embedded in PV2 were recorded in Tris/citrate buffer $(50 \mathrm{mM})$ with $\mathrm{KI}(100 \mathrm{mM})$ as a supporting electrolyte. The CVs of DdHydAB embedded in DV2 were recorded in different electrolytes optimised for the requirements of the individual measurements as indicated. All DET CVs were recorded in a buffer mix containing MES, HEPES, TAPS, CHES, sodium acetate (15 mM each, $\mathrm{pH}$ as indicated) and $\mathrm{NaCl}(100 \mathrm{mM})$ as a supporting electrolyte. 


\section{Preparation of $\mathrm{DdHydAB}$}

$D d \mathrm{HydAB}$ was produced heterologously in E. coli, purified by affinity chromatography, artificially maturated ${ }^{73}$ and converted to an air-stable form as described previously. ${ }^{74}$ The air-stable enzyme reactivates spontaneously in viologen modified films in presence of $\mathrm{H}_{2} \cdot{ }^{35}$

\section{Preparation of PV2/DdHydAB-modified anodes}

The $D d \mathrm{HydAB}[\mathrm{FeFe}]$ hydrogenase was immobilised via physical entrapment in the polymer network. For the preparation of the non-gas breathing anodes, an aqueous solution of PV2 $\left(10 \mu \mathrm{L}, 3 \mathrm{mg} \mathrm{mL}^{-1}\right)$ was mixed with a solution of hydrogenase $(200 \mu \mathrm{M}$ in $50 \mathrm{mM}$ Tris/ $\mathrm{HCl}$ buffer, $\mathrm{pH}$ 7.2). The mixture was immobilised on a glassy carbon electrode $\left(\mathrm{A}_{\mathrm{g}}=\right.$ $0.07 \mathrm{~cm}^{-2}$ ) by drop-casting and dried for at least $2 \mathrm{~h}$ at RT under glove box conditions with a moist atmosphere. To achieve sufficient stability, the anode was pretreated with KI before the biofuel cell experiments (Supplementary Figure 55). For the gas breathing anode a round piece of Carbon Toray Paper (Quintech, Freudenberg Gasdiffusionsanlage, H23-C9, 0.25 mm thick, $\delta=135 \mathrm{~g} \mathrm{~cm}^{-2}, d=2.2 \mathrm{~cm}$ ) was washed with ethanol (p.a.) followed by distilled water. The wet electrode was functionalised with a thin layer of PV2 $(35 \mu \mathrm{g})$. The layer was allowed to dry at $8{ }^{\circ} \mathrm{C}$ overnight. On top of the layer a mixture of PV2 $\left(63 \mu \mathrm{L}, 1.5 \mathrm{mg} \mathrm{mL}^{-1}\right)$ and $D d \mathrm{HydAB}(6 \mu \mathrm{L}, 200 \mu \mathrm{M}$ in $50 \mathrm{mM}$ Tris/HCl buffer, $\mathrm{pH}$ 8) was immobilised by dropcasting and was left to dry at $8{ }^{\circ} \mathrm{C}$ overnight under ambient air leading to catalytically active films with a geometric area of 0.196 to $0.259 \mathrm{~cm}^{2}$.

\section{Preparation of PV2/DdHydAB-modified electrolyser cathode}

A porous carbon foam electrode (MTI, EQ-bcgdl-1400S-LD, porous C, $6 \mathrm{~mm} \times 13 \mathrm{~cm} \mathrm{x}$ $0.454 \mathrm{~mm}$, air permeability $\approx 10 \mathrm{~mL} \mathrm{~cm}^{-2} \mathrm{~s}^{-1}$, porosity $\approx 31 \mu \mathrm{m}$ coated on one side with a Nafion/Teflon-based microporous film of $50 \mu \mathrm{m}$, carbon content $5 \mathrm{mg} \mathrm{cm}^{-2}$ ) was washed with ethanol (p.a.) followed by distilled water. The wet material was functionalised with a thin layer of PV2 (35 $\mu \mathrm{g}$ ) and was allowed to dry at $8{ }^{\circ} \mathrm{C}$ overnight. A mixture of PV2 (63 $\left.\mu \mathrm{L}, 1.5 \mathrm{mg} \mathrm{mL}^{-1}\right)$ and $D d \mathrm{HydAB}(6 \mu \mathrm{L}, 200 \mu \mathrm{M}$ in $50 \mathrm{mM}$ Tris/HCl buffer, $\mathrm{pH} 8)$ was immobilised by drop-casting on top of the underlying polymer layer. The films were left to dry at $8{ }^{\circ} \mathrm{C}$ overnight leading to a functionalised geometric surface area of $0.188 \mathrm{~cm}^{2}$.

\section{Preparation of the bilirubin oxidase modified cathode}

The cathode preparation was adapted from ref $\left[{ }^{57}\right]$. For the efficient orientation of bilirubin oxidase from Myrothecium verrucaria (MvBOx), a sheet of Toray carbon paper $\left(6 \mathrm{~cm}^{2}\right)$ was electrochemically functionalised with negatively charged naphthoate moieties. The carbon paper was immersed in a solution of 5-carboxynaphthalene-2-diazonium tetrafluoroborate $(0.87 \mathrm{mM})$ in $\mathrm{MeCN}$ containing tetrabutylammonium tetrafluoroborate $(100 \mathrm{mM})$ as a supporting electrolyte (for the synthesis of the diazonium salt see ref [57]). The naphthoate was covalently attached by applying 10 reductive potential pulses $(0.5 \mathrm{~s},-0.1 \mathrm{~V}$ vs $\mathrm{Ag} / \mathrm{AgCl}$ $3 \mathrm{M} \mathrm{KCl})$. The residual diazonium salt was washed off with acetonitrile $(10 \times 1 \mathrm{ml})$, followed by ethanol $(10 \times 1 \mathrm{ml})$. The organic solvents were removed by drying the carbon paper for at least two hours under air. The carbon paper was then wetted with potassium phosphate buffer (PB, $5 \mathrm{~mL}, 50 \mathrm{mM}, \mathrm{pH} 7.2)$. A solution of $M v \mathrm{BOx}\left(120 \mu \mathrm{L} ; 2 \mathrm{mg} \mathrm{mL}^{-1}\right)$ in potassium phosphate buffer $(50 \mathrm{mM}, \mathrm{pH} 7.2)$ was drop-cast on the wet sheet. The enzyme was allowed 
to immobilise on the naphthoate moieties for $48 \mathrm{~h}$ at $4{ }^{\circ} \mathrm{C}$. Unbound enzyme was removed by rinsing the electrode with potassium phosphate buffer $(10 \times 1 \mathrm{~mL}, 50 \mathrm{mM}, \mathrm{pH} 7.2)$.

\section{Supplementary Material}

Refer to Web version on PubMed Central for supplementary material.

\section{Acknowledgements}

C.L. and V.F. are supported by CNRS, Aix Marseille Université, Agence Nationale de la Recherche (ANR-15CE05-0020), and the Excellence Initiative of Aix-Marseille University-A*MIDEX, a French "Investissements d'Avenir" programme (ANR-11-IDEX-0001-02). N.P., S.H., and S.S. acknowledge financial support by the ERC starting grant 715900, by the ANR-DFG project SHIELDS (PL 746/2-1) and by RESOLV, funded by the Deutsche Forschungsgemeinschaft (DFG, German Research Foundation) under Germany's Excellence Strategy - EXC-2033 - Projektnummer 390677874. J.A.B. and O.R. are supported by the Max Planck Society and J.A.B. acknowledges funding from the Deutsche Forschungsgemeinschaft (DFG) Priority Programme "Iron-Sulfur for Life: Cooperative Function of Iron-Sulfur Centers in Assembly, Biosynthesis, Catalysis and Disease" (SPP 1927) Project BI 2198/1-1. The authors thank Dr. Adrian Ruff and Leonardo Castaneda-Losada for useful discussions regarding the polymer synthesis, Nina Breuer for the preparation of the hydrogenase, Dr. Bert Mallick for performing the crystal structure measurements, Miriam Sander and Oliver Trost for optimizing the fuel cells, Anna Czepull for optimizing film stability, Dr. Huaiguang Li for help with the CV experiments and Tobias Stalder for solving the crystal structure. The French authors are part of the FrenchBIC network.

\section{Data availability statement}

All source data that support the findings of this study (Data of the Figures 2 - 4, Supplementary Figures 2 - 16, 18 - 21, 23 - 51 and 53 - 55) are available in Zenodo with the identifier 10.5281/zenodo.4421107. Figure 1, Supplementary Figures 1, 22 and 52 are general schemes without underlying data. The underlying data of the crystal structure (Supplementary Figure 5) is deposited in the Cambridge structural database with the identifier CCDC 2046659.

\section{References}

1. Armstrong FA, Hirst J. Reversibility and efficiency in electrocatalytic energy conversion and lessons from enzymes. Proc Natl Acad Sci U S A. 2011; 108:14049-14054. [PubMed: 21844379]

2. Dutta A, Appel AM, Shaw WJ. Designing electrochemically reversible $\mathrm{H}_{2}$ oxidation and production catalysts. Nat Rev Chem. 2018; 2:244-252.

3. Fourmond V, Wiedner ES, Shaw WJ, Léger C. Understanding and design of bidirectional and reversible catalysts of multielectron, multistep reactions. J Am Chem Soc. 2019; 141:11269-11285. [PubMed: 31283209]

4. Priyadarshani $\mathrm{N}$, et al. Achieving reversible $\mathrm{H}_{2} / \mathrm{H}^{+}$interconversion at room temperature with enzyme-inspired molecular complexes: a mechanistic study. ACS Catal. 2016; 6:6037-6049.

5. Dutta A, DuBois DL, Roberts JAS, Shaw WJ. Amino acid modified Ni catalyst exhibits reversible $\mathrm{H}_{2}$ oxidation/production over a broad $\mathrm{pH}$ range at elevated temperatures. Proc Natl Acad Sci U S A. 2014; 111:16286-16291. [PubMed: 25368196]

6. Cunningham DW, Barlow JM, Velasquez RS, Yang J. Reversible and selective $\mathrm{CO}_{2}$ to $\mathrm{HCO}_{2}-$ electrocatalysis near the thermodynamic potential. Angew Chem Int Ed. 2019; 59:4443-4447.

7. Cunningham DW, Yang JY. Kinetic and mechanistic analysis of a synthetic reversible $\mathrm{CO}_{2} / \mathrm{HCO}_{2}$ electrocatalyst. Chem Commun. 2020; 56:12965-12968.

8. Le Goff A, et al. From hydrogenases to noble metal-free catalytic nanomaterials for $\mathrm{H}_{2}$ production and uptake. Science. 2009; 326:1384-1387. [PubMed: 19965754]

9. Del Barrio M, et al. Electrochemical investigations of hydrogenases and other enzymes that produce and use solar fuels. Acc Chem Res. 2018; 51:769-777. [PubMed: 29517230] 
10. Siritanaratkul B, et al. Transfer of photosynthetic $\mathrm{NADP}^{+} / \mathrm{NADPH}$ recycling activity to a porous metal oxide for highly specific, electrochemically-driven organic synthesis. Chem Sci. 2017; 8:4579-4586. [PubMed: 30155220]

11. Léger C, et al. Enzyme electrokinetics: energetics of succinate oxidation by fumarate reductase and succinate dehydrogenase. Biochemistry. 2001; 40:11234-11245. [PubMed: 11551223]

12. Wang VCC, Can M, Pierce E, Ragsdale SW, Armstrong FA. A unified electrocatalytic description of the action of inhibitors of nickel carbon monoxide dehydrogenase. J Am Chem Soc. 2013; 135:2198-2206. [PubMed: 23368960]

13. Bassegoda A, Madden C, Wakerley DW, Reisner E, Hirst J. Reversible interconversion of $\mathrm{CO}_{2}$ and formate by a molybdenum-containing formate dehydrogenase. J Am Chem Soc. 2014; 136:1547315476. [PubMed: 25325406]

14. Zu Y, Shannon RJ, Hirst J. Reversible, electrochemical interconversion of NADH and NAD by the catalytic (I $\lambda$ ) subcomplex of mitochondrial NADH:ubiquinone Oxidoreductase (Complex I). J Am Chem Soc. 2003; 125:6020-6021. [PubMed: 12785808]

15. McKone JR, Lewis NS, Gray HB. Will solar-driven water-splitting devices see the light of day? Chem Mater. 2014; 26:407-414.

16. Helm ML, Stewart MP, Bullock RM, DuBois MR, DuBois DL. A synthetic nickel electrocatalyst with a turnover frequency above $100,000 \mathrm{~s}^{-1}$ for $\mathrm{H}_{2}$ production. Science. 2011; 333:863-866. [PubMed: 21836012]

17. Hoffert WA, Roberts JAS, Morris Bullock R, Helm ML. Production of $\mathrm{H}_{2}$ at fast rates using a nickel electrocatalyst in water-acetonitrile solutions. Chem Commun. 2013; 49:7767-7769.

18. Dutta A, Roberts JAS, Shaw WJ. Arginine-containing ligands enhance H2 oxidation catalyst performance. Angew Chem Int Ed. 2014; 53:6487-6491.

19. Cracknell JA, Vincent KA, Armstrong FA. Enzymes as working or inspirational electrocatalysts for fuel cells and electrolysis. Chem Rev. 2008; 108:2439-2461. [PubMed: 18620369]

20. Wakerley DW, Reisner E. Oxygen-tolerant proton reduction catalysis: much $\mathrm{O}_{2}$ about nothing? Energy Environ Sci. 2015; 8:2283-2295.

21. Cooney MJ, Svoboda V, Lau C, Martin G, Minteer SD. Enzyme catalysed biofuel cells. Energy Environ Sci. 2008; 1:320-337.

22. Barton SC, Gallaway J, Atanassov P. Enzymatic biofuel cells for implantable and microscale devices. Chem Rev. 2004; 104:4867-4886. [PubMed: 15669171]

23. Leech D, Kavanagh P, Schuhmann W. Enzymatic fuel cells: recent progress. Electrochim Acta. 2012; 84:223-234.

24. $\mathrm{Li} \mathrm{H}$, et al. Complete protection of $\mathrm{O}_{2}$-sensitive catalysts in thin films. J Am Chem Soc. 2019; 141:16734-16742. [PubMed: 31525046]

25. Li H, et al. Suppressing hydrogen peroxide generation to achieve oxygen-insensitivity of a [NiFe] hydrogenase in redox active films. Nat Commun. 2020; 11:920. [PubMed: 32060304]

26. Plumeré N, et al. A redox hydrogel protects hydrogenase from high-potential deactivation and oxygen damage. Nat Chem. 2014; 6:822-827. [PubMed: 25143219]

27. Shiraiwa $\mathrm{S}$, et al. Reactivation of standard [NiFe]-hydrogenase and bioelectrochemical catalysis of proton reduction and hydrogen oxidation in a mediated-electron-transfer system. Bioelectrochemistry. 2018; 123:156-161. [PubMed: 29753939]

28. Yuan M, et al. Creating a low-potential redox polymer for efficient electroenzymatic $\mathrm{CO}_{2}$ reduction. Angew Chem Int Ed. 2018; 57:6582-6586.

29. Szczesny J, et al. Electroenzymatic $\mathrm{CO}_{2}$ fixation using redox polymer/enzyme-modified gas diffusion electrodes. ACS Energy Lett. 2019:321-327.

30. Sakai K, Kitazumi Y, Shirai O, Takagi K, Kano K. High-power formate/dioxygen biofuel cell based on mediated electron transfer type bioelectrocatalysis. ACS Catal. 2017; 7:5668-5673.

31. Ruth JC, Milton RD, Gu W, Spormann AM. Enhanced electrosynthetic hydrogen evolution by hydrogenases embedded in a redox-active hydrogel. Chemistry. 2020; 26:7323-7329. [PubMed: 32074397] 
32. Esselborn J, Kertess L, Apfel U-P, Hofmann E, Happe T. Loss of specific active-site iron atoms in oxygen-exposed [FeFe]-hydrogenase determined by detailed X-ray structure analyses. J Am Chem Soc. 2019; 141:17721-17728. [PubMed: 31609603]

33. Kubas A, et al. Mechanism of $\mathrm{O}_{2}$ diffusion and reduction in FeFe hydrogenases. Nat Chem. 2017; 9:88-95. [PubMed: 27995927]

34. Oughli AA, et al. A redox hydrogel protects the $\mathrm{O}_{2}$-sensitive $[\mathrm{FeFe}]$-hydrogenase from Chlamydomonas reinhardtii from oxidative damage. Angew Chem Int Ed. 2015; 54:12329-12333.

35. Oughli AA, Hardt S, Rüdiger O, Birrell JA, Plumeré N. Reactivation of sulfide-protected [FeFe] hydrogenase in a redox-active hydrogel. Chem Commun. 2020; 56:9958-9961.

36. Gallaway JW, Calabrese Barton SA. Kinetics of redox polymer-mediated enzyme electrodes. J Am Chem Soc. 2008; 130:8527-8536. [PubMed: 18540577]

37. Cai R, Minteer SD. Nitrogenase bioelectrocatalysis: from understanding electron-transfer mechanisms to energy applications. ACS Energy Lett. 2018; 3:2736-2742.

38. Bird CL, Kuhn AT. Electrochemistry of the viologens. Chem Soc Rev. 1981; 10:49.

39. Tsujimura S, Fujita M, Tatsumi H, Kano K, Ikeda T. Bioelectrocatalysis-based dihydrogen/ dioxygen fuel cell operating at physiological pH. Phys Chem Chem Phys. 2001; 3:1331-1335.

40. Lojou E, Giudici-Orticoni MT, Bianco P. Direct electrochemistry and enzymatic activity of bacterial polyhemic cytochrome $c_{3}$ incorporated in clay films. J Electroanal Chem. 2005; 579:199-213.

41. Tatsumi H, Takagi K, Fujita M, Kano K, Ikeda T. Electrochemical study of reversible hydrogenase reaction of Desulfovibrio vulgaris cells with methyl viologen as an electron carrier. Anal Chem. 1999; 71:1753-1759. [PubMed: 10330906]

42. Fultz ML, Durst RA. Mediator compounds for the electrochemical study of biological redox systems: a compilation. Anal Chim Acta. 1982; 140:1-18.

43. Alber KS, Hahn TK, Jones ML, Fountain KR, Van Galen DA. The electrocatalyzed reduction of fumaronitrile in aqueous solution by $4,4^{\prime}$-dimethyl-1, $1^{\prime}$-trimethylene-2, $2^{\prime}$-dipyridinium ion. $\mathrm{J}$ Electroanal Chem. 1995; 383:119-126.

44. Li H, et al. Preventing the coffee-ring effect and aggregate sedimentation by in situ gelation of monodisperse materials. Chem Sci. 2018; 9:7596-7605. [PubMed: 30393519]

45. Buesen D, Li H, Plumeré N. The electron as a probe to measure the thickness distributions of electroactive films. Chem Sci. 2020; 11:937-946. [PubMed: 33144933]

46. Caserta G, et al. Engineering an [FeFe]-hydrogenase: do accessory clusters influence $\mathrm{O}_{2}$ resistance and catalytic bias? J Am Chem Soc. 2018; 140:5516-5526. [PubMed: 29595965]

47. Léger C, Jones AK, Roseboom W, Albracht SPJ, Armstrong FA. Enzyme electrokinetics: hydrogen evolution and oxidation by Allochromatium vinosum [NiFe]-hydrogenase. Biochemistry. 2002; 41:15736-15746. [PubMed: 12501202]

48. Ceccaldi P, Schuchmann K, Müller V, Elliott SJ. The hydrogen dependent $\mathrm{CO}_{2}$ reductase: the first completely CO tolerant FeFe-hydrogenase. Energy Environ Sci. 2017; 10:503-508.

49. Butt JN, Filipiak M, Hagen WR. Direct electrochemistry of Megasphaera elsdenii iron hydrogenase. Definition of the enzyme's catalytic operating potential and quantitation of the catalytic behaviour over a continuous potential range. Eur J Biochem. 1997; 245:116-122. [PubMed: 9128731]

50. Andrieux CP, Dumas-Bouchiat JM, Savéant JM. Catalysis of electrochemical reactions at redox polymer electrodes: Kinetic model for stationary voltammetric techniques. J Electroanal Chem Interfacial Electrochem. 1982; 131:1-35.

51. Bartlett PN, Pratt KFE. Theoretical treatment of diffusion and kinetics in amperometric immobilized enzyme electrodes Part I: redox mediator entrapped within the film. J Electroanal Chem. 1995; 397:61-78.

52. Fourmond V, et al. Mechanism of protection of catalysts supported in redox hydrogel films. J Am Chem Soc. 2015; 137:5494-5505. [PubMed: 25835569]

53. Andrieux CP, Dumas-Bouchiat JM, Saveant JM. Catalysis of electrochemical reactions at redox polymer electrodes: effect of the film thickness. J Electroanal Chem Interfacial Electrochem. 1980; 114:159-163. 
54. Fourmond V, et al. Steady-state catalytic wave-shapes for 2-electron reversible electrocatalysts and enzymes. J Am Chem Soc. 2013; 135:3926-3938. [PubMed: 23362993]

55. Fourmond V, Léger C. Modelling the voltammetry of adsorbed enzymes and molecular catalysts. Curr Opin in Electrochem. 2017; 1:110-120.

56. Lampret $\mathrm{O}$, et al. Interplay between $\mathrm{CN}$-ligands and the secondary coordination sphere of the $\mathrm{H}$ cluster in [FeFe]-hydrogenases. J Am Chem Soc. 2017; 139:18222-18230. [PubMed: 29179539]

57. Lalaoui N, Holzinger M, Le Goff A, Cosnier S. Diazonium functionalisation of carbon nanotubes for specific orientation of multicopper oxidases: controlling electron entry points and oxygen diffusion to the enzyme. Chemistry. 2016; 22:10494-10500. [PubMed: 27328033]

58. Mazurenko I, Wang X, de Poulpiquet A, Lojou E. $\mathrm{H}_{2} / \mathrm{O}_{2}$ enzymatic fuel cells: from proof-ofconcept to powerful devices. Sustain Energy Fuels. 2017; 1:1475-1501.

59. Dos Santos L, Climent V, Blanford CF, Armstrong FA. Mechanistic studies of the 'blue' Cu enzyme, bilirubin oxidase, as a highly efficient electrocatalyst for the oxygen reduction reaction. Phys Chem Chem Phys. 2010; 12:13962-13974. [PubMed: 20852807]

60. Del Barrio M, et al. Interaction of the H-cluster of FeFe hydrogenase with halides. J Am Chem Soc. 2018; 140:5485-5492. [PubMed: 29590528]

61. Singh MR, Clark EL, Bell AT. Effects of electrolyte, catalyst, and membrane composition and operating conditions on the performance of solar-driven electrochemical reduction of carbon dioxide. Phys Chem Chem Phys. 2015; 17:18924-18936. [PubMed: 26103939]

62. Jouny M, Luc W, Jiao F. General techno-economic analysis of $\mathrm{CO}_{2}$ electrolysis systems. Ind Eng Chem Res. 2018; 57:2165-2177.

63. Ciaccafava A, et al. Electrochemistry, AFM, and PM-IRRA spectroscopy of immobilized hydrogenase: role of a hydrophobic helix in enzyme orientation for efficient $\mathrm{H}_{2}$ oxidation. Angew Chem Int Ed. 2012; 51:953-956.

64. Xu L, Armstrong FA. Optimizing the power of enzyme-based membrane-less hydrogen fuel cells for hydrogen-rich $\mathrm{H}_{2}$-air mixtures. Energy Environ Sci. 2013; 6:2166-2171.

65. Xia H-Q, et al. Dual gas-diffusion membrane- and mediatorless dihydrogen/air-breathing biofuel cell operating at room temperature. J Power Sources. 2016; 335:105-112.

66. So K, et al. Direct electron transfer-type dual gas diffusion $\mathrm{H}_{2} / \mathrm{O}_{2}$ biofuel cells. J Mater Chem A Mater Energy Sustain. 2016; 4:8742-8749.

67. Gentil S, et al. Oriented immobilization of [NiFeSe] hydrogenases on covalently and noncovalently functionalized carbon nanotubes for $\mathrm{H}_{2}$ /Air enzymatic fuel cells. ACS Catal. 2018; 8:3957-3964.

68. Szczesny J, et al. A gas breathing hydrogen/air biofuel cell comprising a redox polymer/ hydrogenase-based bioanode. Nat Commun. 2018; 9:4715. [PubMed: 30413708]

69. Conzuelo F, Marković N, Ruff A, Schuhmann W. The open circuit voltage in biofuel cells: nernstian shift in pseudocapacitive electrodes. Angew Chem Int Ed. 2018; 57:13681-13685.

70. Shleev S, et al. Oxygen electroreduction versus bioelectroreduction: direct electron transfer approach. Electroanalysis. 2016; 28:2270-2287.

71. Sakai K, et al. Interconversion between formate and hydrogen carbonate by tungsten-containing formate dehydrogenase-catalyzed mediated bioelectrocatalysis. Sensing and Bio-Sensing Research. 2015; 5:90-96.

72. Léger C, Lederer F, Guigliarelli B, Bertrand P. Electron flow in multicenter enzymes: theory, applications, and consequences on the natural design of redox chains. J Am Chem Soc. 2006; 128:180-187. [PubMed: 16390145]

73. Birrell JA, et al. Artificial maturation of the highly active heterodimeric [FeFe] hydrogenase from Desulfovibrio desulfuricans ATCC 7757. Isr J Chem. 2016; 56:852-863.

74. Rodríguez-Maciá $\mathrm{P}$, et al. Sulfide protects $[\mathrm{FeFe}]$ hydrogenases from $\mathrm{O}_{2}$. J Am Chem Soc. 2018; 140:9346-9350. [PubMed: 30008217] 

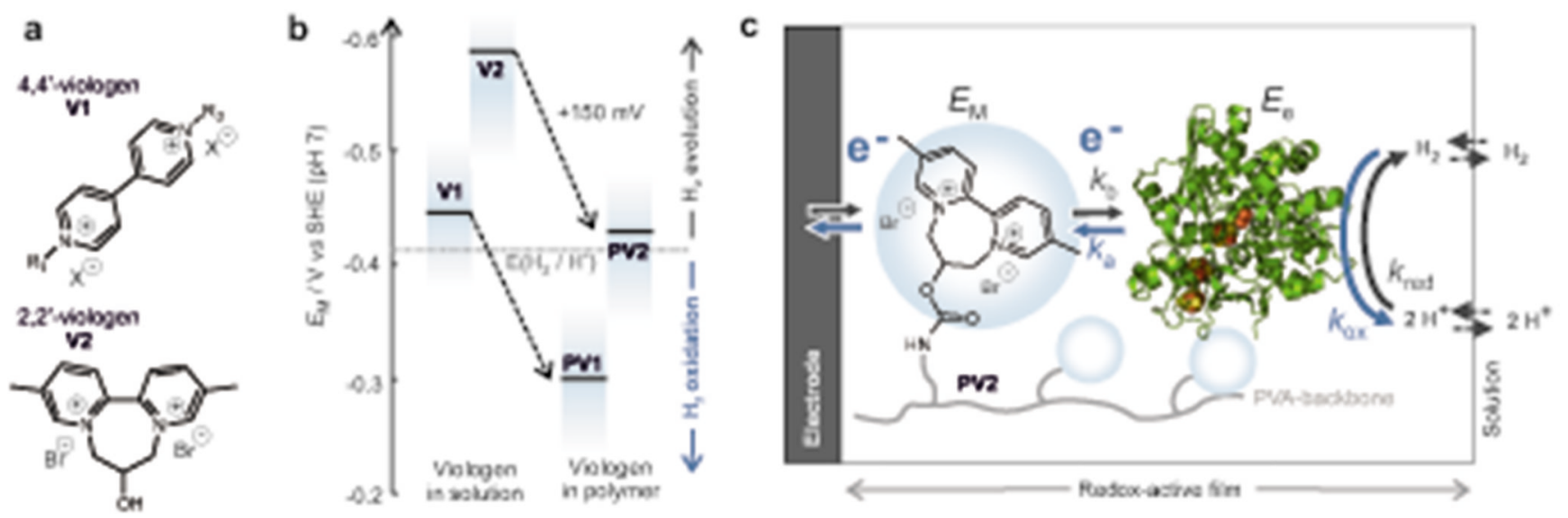

Fig. 1. Redox-active polymers for reversible hydrogenase catalysis.

a. Structure of 4,4'-viologen (V1) and 2,2'-viologen (V2) moieties used in redox polymers for immobilisation of hydrogenase. $\mathbf{b}$. Redox potential of freely diffusing viologens and of their polymer-bound analogues with respect to the $2 \mathrm{H}^{+} / \mathrm{H}_{2}$ Nernst potential $\left(E\left(2 \mathrm{H}^{+} / \mathrm{H}_{2}\right)\right)$. The shaded areas illustrate the range of redox potentials observed for these viologens and viologen modified polymer analogues (depending on the nature of substituents, electrolyte composition, and polymer backbone); the black lines show the redox potentials of the 4,4'methylviologen $\mathbf{V} \mathbf{1}$ with $\mathrm{R}_{1}=\mathrm{R}_{2}=$ Methyl (reported in ref [38]), the 2,2'-methylviologen V2, the 4,4'-methylviologen-based polymer PV1 (reported in ref [26] and the 2,2'methylviologen-based polymer PV2 (structure in Supplementary Figure 1). The backbone of PV2 is polyvinyl-alcohol (PVA). c. Scheme of the mediated electron transfer (MET) and catalysis in the PV2 based redox-hydrogel embedding [FeFe] hydrogenase from Desulfovibrio Desulfuricans (DdHydAB). The kinetic model developed in the Supporting Information relates the catalytic current to the values of the bimolecular electron transfer rate constants $k_{a}$ and $k_{b}$, the $1^{\text {st }}$ order catalytic rate constants $k_{a x}$ and $k_{r e d}$, and the redox potentials of the 2,2'-methylviologen mediator $\left(E_{\mathrm{M}}\right)$ and the enzyme $\left(E_{\mathrm{e}}\right)$. 

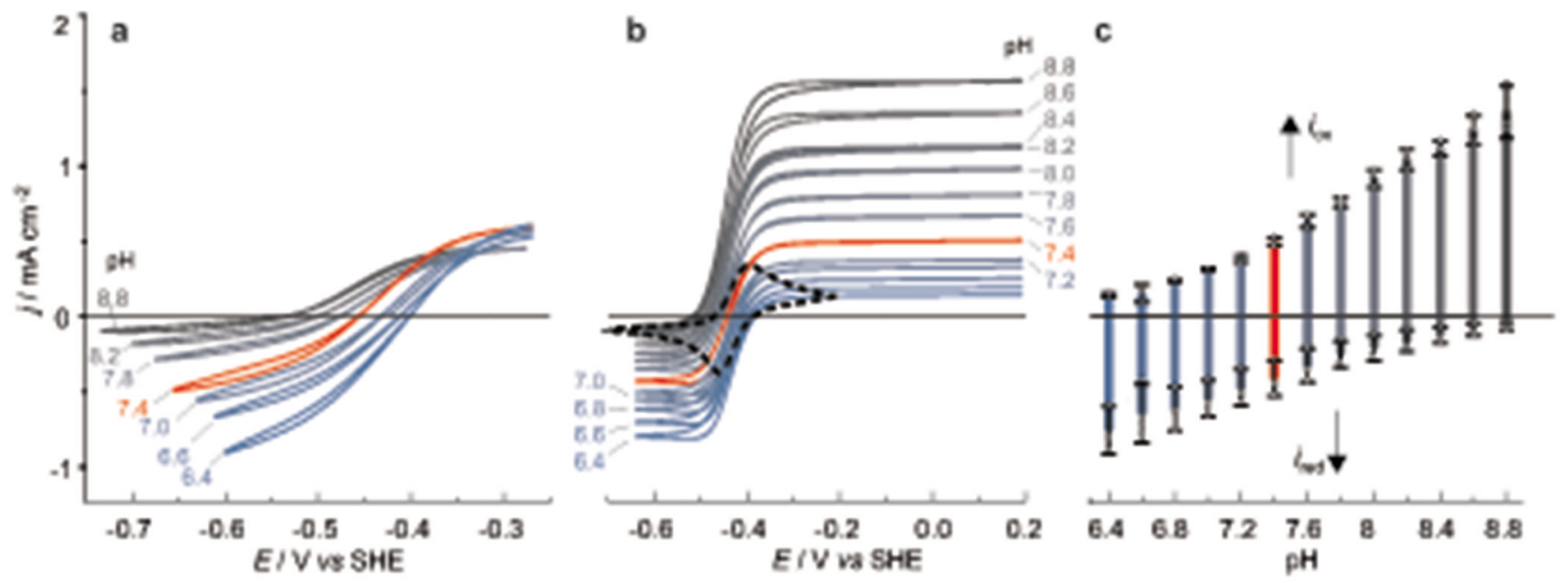

Fig. 2. Direct and mediated electrochemical responses of Desulfovibrio desulfuricans (DdHydAB) hydrogenase.

a. Cyclic voltammograms (CVs) of reversible hydrogen oxidation and production under conditions of direct electron transfer (DET) with a rotating pyrolytic graphite edge disc electrode $\left(d=3 \mathrm{~mm}\right.$, scan rate $=10 \mathrm{mV} \mathrm{s}^{-1}, T=25^{\circ} \mathrm{C}, p\left(\mathrm{H}_{2}\right)=1 \mathrm{~atm}, \mathrm{pH}$ as indicated $)$. CVs obtained for smaller $\mathrm{pH}$ increments are shown in Supplementary Figure 44; b. CVs obtained with the enzyme embedded in a redox hydrogel of PV2 supported on a rotating glassy carbon disc electrode $\left(d=3 \mathrm{~mm}\right.$, scan rate $=10 \mathrm{mV} \mathrm{s}^{-1}, T=25^{\circ} \mathrm{C}, P\left(\mathrm{H}_{2}\right)=1 \mathrm{~atm}, \mathrm{pH}$ as indicated). The non-catalytic $\mathrm{CV}$ of the polymer film without enzyme is shown as a dashed line. The measurement at $\mathrm{pH} 7.4$ used for comparison to simulation in Fig. 3 is shown in red; c. bar diagram of the limiting, mediated $\mathrm{H}_{2}$ oxidation and production current $\left(i_{\text {ox }}\right.$ and $i_{\text {red, }}$, as defined in Fig. 3b) as a function of $\mathrm{pH}$. Data are presented as mean values +/- SD of three independent experiments $(n=3)$. The individual data points are shown as open squares. The catalytic currents are stable for at least 100 cycles over the course of 3 hours (Supplementary Figure $39 \mathrm{a}, \mathrm{b}$ ) over the entire $\mathrm{pH}$ range. 

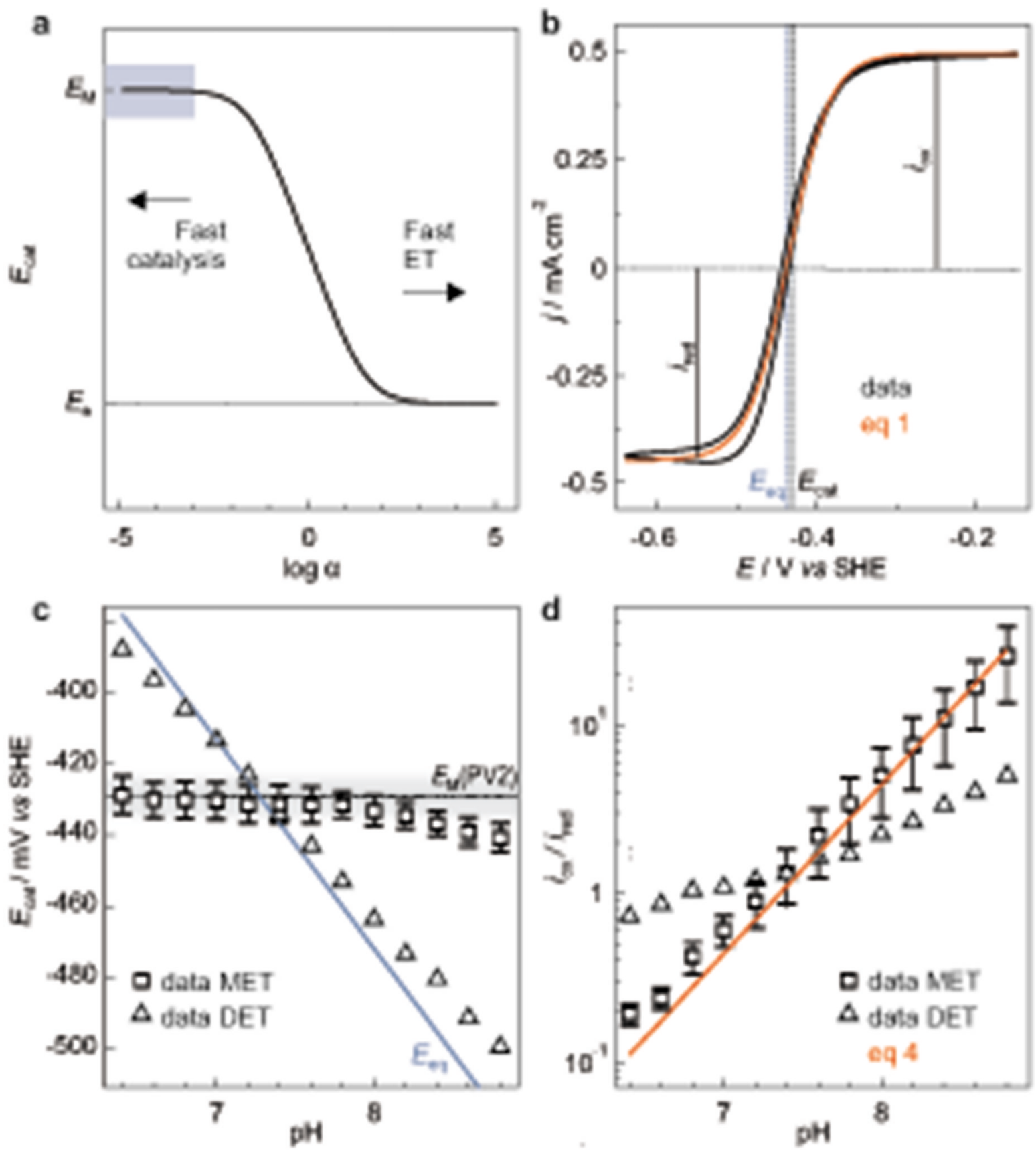

Fig. 3. Modeling of the mediated catalytic CVs.

a. Effect of changing the rate of intermolecular ET between the mediator and the catalyst on the value of the catalytic $\alpha=A^{\sum} \sqrt{k_{a} k_{b}} /\left(k_{\mathrm{Ox}}+k_{\text {red }}\right)$ potential, as predicted by Equation 2 . The parameter measures the competition between intermolecular ET and catalysis. The catalytic potential $E_{\text {cat }}$ continuously changes from the mediator potential $E_{\mathrm{M}}$ to the enzyme potential $E_{\mathrm{e}}$ as a increases. b. Equation 1 (red) is fitted to the experimental MET CV (black, data from Fig. $2 \mathrm{~b}$ at $\mathrm{pH}$ 7.4) with $i_{\text {ox }}$ and $i_{\text {red }}$ being the plateau catalytic currents of hydrogen oxidation and hydrogen evolution, respectively. Fit parameters: $i_{\mathrm{ox}}=0.494 \pm 0.001 \mathrm{~mA}$ 
$\mathrm{cm}^{-2}, i_{\text {red }}=0.442 \pm 0.002 \mathrm{~mA} \mathrm{~cm}{ }^{-2}, E_{\text {cat }}=-0.435 \pm 0.001 \mathrm{~V}$. c. Experimental catalytic potential (the half wave potential $E_{\text {cat }}$ ) as a function of $\mathrm{pH}$. The dashed line is the potential of $E_{\mathrm{M}}(\mathrm{PV} 2)$ (mean value from four individual polymer batches $(n=4)$ shown in Supplementary Figure 33) with its standard deviation indicated by the shaded area. The solid blue line is the calculated $E_{\text {eq }}$. d. Experimental catalytic bias (the ratio of $i_{\text {ox }} / i_{\text {red }}$ defined in panel $b$ ) as a function of $\mathrm{pH}$. The prediction of Equation 4 (red line) is calculated from the $\mathrm{pH}$-dependent $2 \mathrm{H}^{+} / \mathrm{H}_{2}$ equilibrium potential $\left(E_{\text {eq }}\right.$ ). The values of the catalytic potential and of the catalytic bias are obtained from the mediated electron transfer (MET) CVs from Fig. $2 \mathrm{~b}$ and direct electron transfer (DET) CVs (triangles) from Fig. 2a and Supplementary Figure 44. For the MET-process $E_{\text {cat }}$ and $i_{\text {ox }} / i_{\text {red }}$ are presented as mean values $+/$ - SD derived from three independent experiments $(n=3)$. The corresponding data for DV2 are shown in Supplementary Figure 43. 

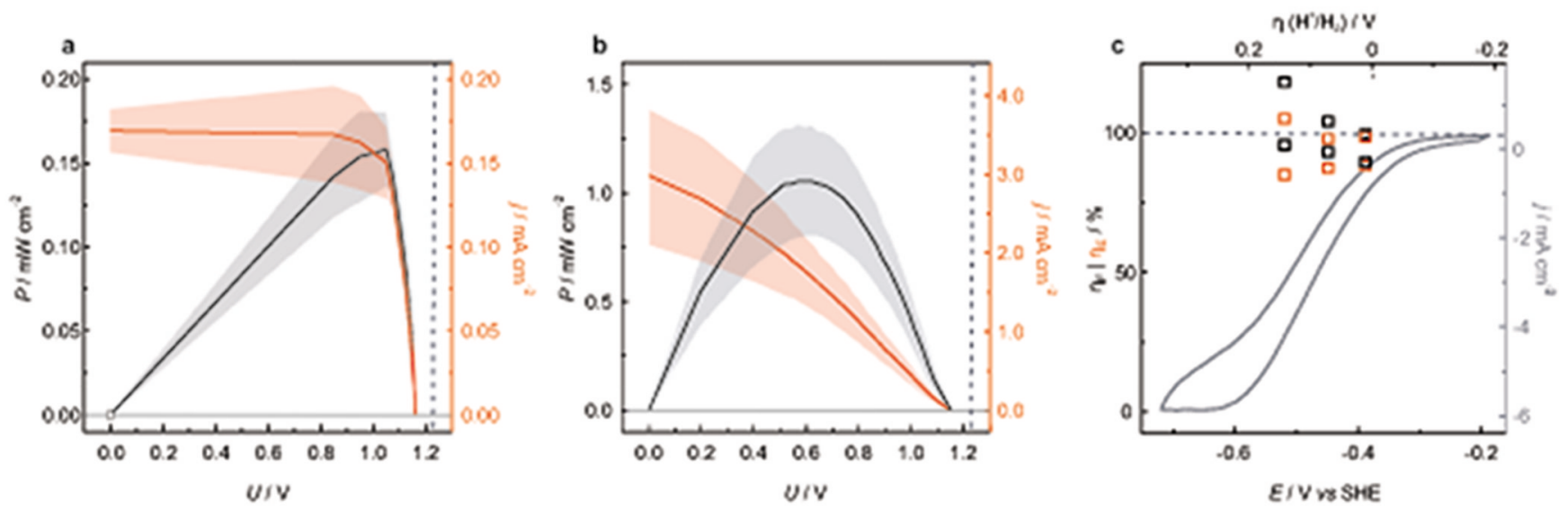

Fig. 4. Reversible hydrogenase electrode for $\mathrm{H}_{2} / \mathrm{O}_{2}$ biofuel cell and electrolyser.

a. Power curve and current / voltage ( $I / U$ )-curve of two-compartment biofuel cells operating with an anode consisting of PV2/DdHydAB on a flat glassy carbon electrode (diameter $=3 \mathrm{~mm}$ ). The setup is schematically shown in Supplementary Figure $51 \mathrm{~b}$. $\mathbf{b}$.

Power curve and $I / U$-curve of two-compartment biofuel cells with an anode consisting of PV2/DdHydAB on a high surface area gas breathing electrode. The setup is schematised in Supplementary Figure 52. For both fuel cell setups, the cathode consisted of bilirubin oxidase immobilised on a high surface Toray paper electrode. The electrolyte of both compartments was potassium phosphate buffer (50 mM, pH 7.4). Averages and standard deviations (shaded areas) were measured from three repetitions of the biofuel cell experiments shown in Supplementary Figure 51c,d (flat electrodes) and Supplementary Figure $53 \mathrm{~b}$ (gas breathing electrodes). The thermodynamic limit of a $\mathrm{H}_{2} / \mathrm{O}_{2}$-fuel cell (1.23 $\mathrm{V})$ is denoted as grey, dashed line. c. Faraday efficiency $\left(\eta_{\mathrm{F}}\right.$, black squares, defined as the ratio of charge used for $\mathrm{H}_{2}$ production over charge passing the electrode), energy efficiency of the cathodic half-cell ( $\eta_{E}$, red squares, calculated by considering the cathodic overpotential and assuming a reversible oxygen evolving half cell ${ }^{61,62}$ ) and cyclic voltammogram (grey solid line) of the electrolyser half-cell based on a PV2/DdHydAB film immobilised on a MTI carbon foam electrode operating in Tris-citrate buffer $(200 \mathrm{mM}$; $\mathrm{pH}$ 6.4) with $\mathrm{KCl}(100 \mathrm{mM})$. Overpotentials $(\eta)$ are with reference to the $2 \mathrm{H}^{+} / \mathrm{H}_{2}$ redox couple. The setup is schematically shown in Supplementary Figure 54a. Hydrogen was quantified by gas chromatography (Supplementary Figure 54d). Data were collected from two individual electrodes per overpotential value (six electrodes in total). 